Relations industrielles

Industrial Relations

\title{
Metzgar, Jack, Striking Steel: Solidarity Remembered
}

\section{Jean Gérin-Lajoie}

Volume 55, numéro 4, 2000

URI : https://id.erudit.org/iderudit/051360ar

DOI : https://doi.org/10.7202/051360ar

Aller au sommaire du numéro

Éditeur(s)

Département des relations industrielles de l'Université Laval

ISSN

0034-379X (imprimé)

1703-8138 (numérique)

Découvrir la revue

Citer ce compte rendu

Gérin-Lajoie, J. (2000). Compte rendu de [Metzgar, Jack, Striking Steel: Solidarity Remembered]. Relations industrielles / Industrial Relations, 55(4), 777-777.

https://doi.org/10.7202/051360ar

Tous droits réservés (C) Département des relations industrielles de l'Université Laval, 2000
Ce document est protégé par la loi sur le droit d'auteur. L'utilisation des services d'Érudit (y compris la reproduction) est assujettie à sa politique d'utilisation que vous pouvez consulter en ligne.

https://apropos.erudit.org/fr/usagers/politique-dutilisation/ 


\section{Striking Steel : Solidarity Remembered \\ par Jack METZGAR, Philadelphia : Temple University Press, 2000, 264 p., ISBN 1-56639-738-3 (alk. paper) et ISBN 1-56639-739-1 (pbk. : alk. paper).}

Ce beau livre est à la fois attachant, informatif et polémique. Attachant parce que l'auteur renoue avec les souvenirs chaleureux et les désaccords d'avec son père, militant syndical et agent de griefs dans une usine de U.S. Steel à Johnstown en Pennsylvanie, c'est-à-dire au cœur de la sidérurgie américaine d'il y a un demi-siècle. Informatif, parce que l'auteur documente avec compétence la grève la plus importante - un demimillion de travailleurs de la sidérurgie pendant trois mois et demie en 1959 de toute l'histoire américaine. Polémique, puisque l'auteur vise à réhabiliter, non seulement l'importance sociale, mais aussi l'identité de la classe ouvrière américaine - où il est né - occultée par le culte et l'hégémonie de la classe moyenne professionnelle, dont il fait maintenant partie. Riche est son menu.

Attachant, certes ce livre l'est. Les souvenirs personnels et familiaux foisonnent. Le ressentiment envers son père dominateur et prédicateur est abondamment souligné par l'auteur du livre. La mère, la famille, la parenté, les voisins et les amis sont présents, nommés, racontés. Un conteur parfois merveilleux. L'auteur y puise avec talent son appréciation-beaucoup plus tardive-de la négociation quotidienne de l'organisation et des rythmes du travail, entre travailleurs et entre travailleurs et superviseurs avant 1960 . Tout n'était pas rose. Tout n'était pas noir. Le pouvoir était partagé. Le partage était très diversifié. Les souvenirs de son père, les entrevues subséquentes de travailleurs sont éloquents.
Informatif ce livre l'est aussi. Il documente avec compétence et discernement l'enjeu central de cette grève, c'est-à-dire la volonté patronale d'affaiblir la section 2-B de la convention collective, qui permettait ce partage du pouvoir dans l'organisation du travail. En effet, cette clause permettait à un travailleur ou à un syndicat local de contester une réorganisation du travail, ce qui pouvait forcer l'employeur à en justifier le bien-fondé. Cette clause, et le partage du pouvoir qu'elle permettait, datait de 1947. Quand cette longue grève se termina, cette clause était encore intacte, au grand chagrin des employeurs de la sidérurgie. Ce livre documente aussi le contexte de la présence syndicale sur les lieux du travail, du moins jusqu'à l'effondrement de la sidérurgie américaine en 1982. Et, de plus, il documente les péripéties politiques internes au sein de ce syndicat qui élit son président au suffrage universel.

Enfin, ce livre est aussi polémique. Il vise de façon explicite à réhabiliter l'identité et les valeurs de la classe ouvrière américaine, l'importance humaine de sa présence quotidienne sur les lieux du travail, et l'importance sociale de la force du syndicalisme avant son déclin récent. Il vise aussi à dénoncer l'emprise de la classe moyenne professionnelle qu'il rend responsable de ce que l'existence et le rôle de la classe ouvrière dans l'histoire de la société américaine aient été occultés, à un point tel qu'ils ont sombré dans l'oubli.

Jean Gérin-LaJoIe École des H.E.C. 